\title{
Fundamental Key Issues and Analysis of Symmetrical Current Components in Micro-Grids
}

\author{
Mohammad Reza Miveh ${ }^{1}$, Sohrab Mirsaeidi ${ }^{2}$, Majid Gandomkar ${ }^{3}$ \\ 1,2 Department of Electrical Engineering, Komijan Branch, Islamic Azad Univesity, Komijan, Iran. \\ ${ }^{3}$ Department of Electrical Engineering, Saveh Branch, Islamic Azad Univesity, Saveh, Iran.
}

\begin{abstract}
Micro-grids are becoming increasingly popular to consumers and as such in the future, a great number of them will be installed at consumer's sites. In this way, conventional distribution grid structures that accept distributed generation connections may face serious problems when their grid control and protection functions become more complicated. These problems have led to a new trend of generation power locally at distribution voltage level by using non-conventional sources like wind power, fuel cells, micro-turbines and biogas and their integration into the utility distribution system. Micro-grids can cause several fundamental problems in its system and grid control when operate as autonomous mode. This paper is a review of fundamental key issues on micro-grids with respect to voltage and frequency flow grid control and protection of micro-grids. Moreover, in the paper the symmetrical current components are analyzed on a larger system of distribution network. All of the studies are simulated using DIgSILENT PowerFactory to establish claims in this paper.
\end{abstract}

Keywords-Micro-grid, Protection, Symmetrical Current Components, Distributed Generation.

\section{INTRODUCTION}

Due to the increased demand for energy and concern over global climate change, Distributed Energy Resources (DERs) such as fuel-cells, wind and solar have a large utilization nowadays. Meanwhile, the microgrid was proposed to manage multiple DGs and local loads efficiently [1]. Micro-grids are small-scale, LV combined heat and power (CHP) supply networks designed to supply electrical and heat loads for a small community, such as a housing estate or a suburban locality, or an academic or public community such as a university or school, a commercial area, an industrial site, a trading estate or a municipal region [2]. Microgrid can operate connected with the larger grid or islanded in the event of a grid fault.

Generally, it connects to the main grid at the point of common coupling. The micro-grid concept enables high penetration of DGs without requiring re-design of the distribution scheme. DGs and corresponding loads can be autonomously separated from the distribution scheme to isolate the micro-grid's load from the disturbance during disturbances. It will intentionally disconnect when the grid power quality falls below certain standard [3]. A micro-grid is designed to seamlessly separate from the grid when problems in the utility grid arise, reconnecting again once these problems are resolved. Normally, in grid connected mode, the micro-sources act as constant power sources, which are grid controlled to inject the demanded power into the grid structure. In autonomous mode, micro-sources are grid controlled to supply all the power needed by the local loads while maintaining the voltage and frequency flow within the acceptable operating limits [4]. Autonomous system is realized by opening the static switch, which disconnects the micro-grid from the main grid as shown in Fig.1.When the micro-grid isolate from the main grid, the micro sources-supplies to the scheme are responsible for maintaining the voltage and frequency flow. The bidirectional power flow for both import and export of power is possible during grid-interconnected system. In event of faults, isolation for micro-grid as well as resynchronization is achievable for islanded system.

During islanding, each distributed generation unit is able to balance power and share loads within the micro-grid scheme [3]. The increased penetration of distributed generation in micro-grid scheme may provide several fundamental problems in the system of the grid, such as steady state and transient over or undervoltages at the point of connection [5]. The grid control and protection of the micro-grid as an autonomous mode will also present challenging problems [6]. This paper is a review of fundamental key issues on micro- 
grid with respect to voltage and frequency flow grid control and protection of micro-grids. Moreover, in the paper we analyze symmetrical current components on a larger system of distribution network.

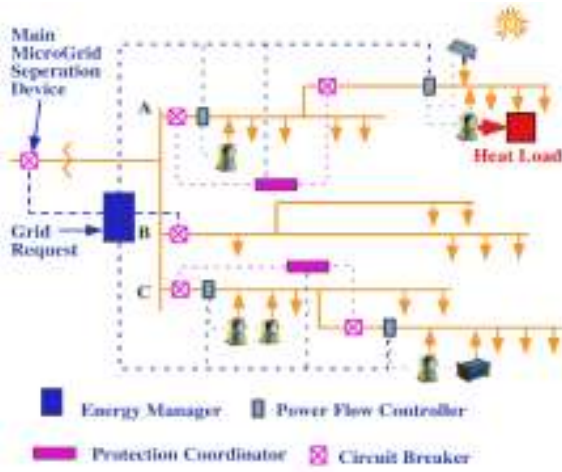

Figure-1. Micro-grid architecture

\section{MICRO-GRID RESEARCH PROJECTS}

The micro-grid projects upon on modeling study and hardware laboratory projects are currently in progress to conduct field test on micro-grid applications such as in Europe, the United State, Japan and Canada. In the European Union (EU), the project was led by the National Fundamental University of Athens (NTUA) together with research institutions and universities. The project was involved on simulation and demonstrates distributed micro-grid system on laboratory grid scales.

The project was successfully completed providing several innovative fundamental solutions, which include the development of islanded and interconnected operating philosophies, local black-start strategies, and grounding and protection schemes, methods for quantification of reliability benefits. The other achievements of this project are to standardize the fundamental and commercial protocols and hardware to allow easy installation of distributed generation with plug and play capabilities. EU demonstration sites are taking place in Greece, Netherlands, Germany, Denmark and Spain.

The R\&D activities in the United State on distributed micro-grids research program was supported both by the US Department of Energy \& California Energy Commission. The most well-known US distributed micro-grid R\&D effort has been pursued under the Consortium for Electric Reliability Methodology Solution which was established in 1999. The Certs distributed micro-grid is intended to separate from normal utility service during a disruption and continue to serve its critical internal loads until acceptable utility service is restored.

Actually, the function provided by the Certs distributed micro-grid is purposely to save cost and no single device is essential for system, creating a robust scheme. The reliability of the Certs distributed microgrid has been well demonstrated in terms of simulation and the bench testing of a laboratory grid scale test scheme at the University of Wisconsin, Madison. Full-grid scale testing on the Certs distributed micro-grid concept has been installed at the Dolan Methodology Center in Columbus Ohio, which is operated by American Electric Power. The Certs distributed micro-grid has presents unique electrical analysis key issues such as contain three phase, single phase and variety of sources interconnected by power electronic devices employing different grid control approaches. The modeling approach enables analysis of a variety of issue such as prediction and evaluation of imbalance, asymmetries, generation-load grid control and dynamic voltage.

In Japan the new energy and industrial methodology development organization and the ministry of economy, trade and industry started three demonstrations under its regional power grid with renewable energy resources project in 2003. Field tests were carried out by integrating new energy sources into a local distribution grid structure.

The distributed micro-grid projects were done in Aomori, Aichi and Kyoto [7]. The main achievement is the development of an optimum system and grid control scheme. Even though multiple field-test of distributed micro-grids are demonstrating the fundamental feasibility of distributed micro-grid, but clear economic and environmental benefits have not yet been demonstrated. Method for economic design and optimal system of distributed micro-grid with renewable energy sources were proposed.

The distributed micro-grid R\&D activities in Canada focused on medium voltage and are mostly carried out in collaboration with the electric utility industry, manufacturers and other stakeholders in distributed energy resources integration and utilization. 
Fundamental key issues and analysis of symmetrical current components in micro-grids

The distributed micro-grid R\&D at the Canadian universities has primary focused on development of grid control and protection strategies for autonomous distributed micro-grid system, distributed micro-grid distributed islanding detection methods for parallel micro source in a distributed micro-grid and study the impact of high penetration of distributed generation in existing protection strategies. The Natural Resources Canada has also established collaborations with the utility industry to conduct field tests and experiments on applications of autonomous distributed micro-grid, grid-interfaced distributed micro-grid, planned distributed micro-grid distributed islanding, and prototype testing and performance evaluation.

\section{A. Distributed Micro-grid in use}

Once, nothing more than a sci-fi concept on the drawing board, several communities and universities have taken concrete steps to implement their own distributed micro-grid. One group that has shown considerable interest in recent years is the US military for their bases. This has two distinct but important practical purposes. Military bases need to be fully system at all times and an interruption to its power supply, for whatever reason, could pose a threat to national security. Bases with a reliable power supply also maintain a strategic advantage during times of crisis.

University campuses are another group that draws huge amounts of power from the grid and also require a reliable source of power. Like the military, they too are excellent candidates to pioneer the implementation of distributed micro-grid, albeit for different reasons. The following are a few of the currently system all distributed micro-grid projects.

\section{B. Fort Bragg}

The Fort Bragg Army Base is not only home to the US Special Forces Strategic Command but also the home of the world's largest distributed micro-grid. The base, which is some 100 square miles (259 square kilometers), incorporates the use of several sources of energy generation that is fully incorporated into the post's distribution grid structure, information methodology, and communications infrastructure. Fort Bragg has an aggregate on-site power generating scheme that includes 15 diesel generators, one $5 \mathrm{~kW}$ fuel cell, and a 5MW base-loaded gas turbine.

As Fort Bragg uses a time-of-use tariff provided by the local energy utility, when market prices exceed a certain threshold, the base automatically goes into self-generating mode, saving money when the cost of selfgeneration is lower than grid-supplied power. There is also the added benefit that the base can instantly decouple itself from the main grid and start generating its own power should the main grid become compromised for any reason.

\section{KEY ISSUES OF MICRO-GRID}

Fundamental benefits of the micro-grid are a distributed islanding implementation of distributed generation to improve the distribution scheme service quality and increased the power scheme reliability [8]. Micro-grid can be implemented to meet the increasing growth in demand and distributed generation is used to perform special task for micro-grid system such as reactive and active power grid control, ability to correct voltage sags and scheme imbalances $[9,10]$. This section is a review of fundamental key issues on micro-grid with respect to voltage and frequency flow grid control and protection of micro-grid.

\section{MICRO-GRID POWER FLOW}

Nowadays Renewable Energy Sources (RES) are necessity for a sustainable growth with plethora of economic, political and ecological reasons driving their rising exploitation. RES and related fundamental key issues are a subject of intensive research and development activities around the globe. The main fundamental key issue connected with RESs exploitation, besides raising efficiencies of various energy conversions that occur in RES, foremost is their integration in the utility grid. This integration should rely on prediction of RES energy production, significant electricity storage capacities present in the grid, and informationcommunication technologies present throughout the utility grid (smart grid).

A prospective way of renewable energy integration in the utility grid is by local grouping of various RES with storage capacities and loads in a micro-grid an entity that ensures both energy and information connectivity between comprising production/storage/consumption units and which is further able to communicate with the utility grid to which it is connected. The concept of micro-grid has been developed through the last decade [1]. 
The grid control of electrical values in a micro-grid is organized in a hierarchical way [4]. The lower levels are responsible for grid control of power converters that interface RES with the common energy link in the micro-grid.

At these levels, grid controllers keep power flows from/to micro-grid elements and voltage/current values on the common link at the desired values. The upper levels deal with the power flow optimization, i.e. decide on the amount of power exchanged between the micro-grid and the utility grid by grid controlling power flows from/to the micro-grid storage units. The goal of the power flow optimization is to maximize the economic gains obtained through the distributed micro-grid system, while taking into account the technoeconomic constraints of distributed micro-grid system and the prediction of energy production and consumption by the distributed micro-grid production/consumption units. Deterministic power flow optimization is considered where the optimization problem may be recast in the form of a linear program for which readily available, very fast and efficient commercial solvers exist.

Distributed micro-grid has been studied in several research projects. The fundamental key issue on distributed micro-grid is the grid control of the power flow and the grid structure voltage by the power electronic converter. Most grid controllers that have been proposed are based on droop lines [2,6]. During the transition from grid connected to islanded system will cause large mismatches between micro-source and loads, posing a frequency flow and voltage grid control problem [6]. Several protection techniques and grid control strategies have been proposed to ensure a stable system and to protect the micro-sources [11, 12].

\section{MICRO-GRID PROTECTION}

It is important to ensure that the loads, lines and the DG on the island are protected within the microgrid [13]. The two alternative current limiting algorithms to prevent the flow of large line currents and protection of distributed micro-grid during utility-voltage sags [14]. There are as resistance-inductance feed forward and flux-charge-model feedback algorithms, for use with a voltage-source inverter (VSI) connected in series between the micro-source and utility grids.

The resistance-inductance algorithm function which was connected with the micro-source and utility grids is to insert large virtual resistance-inductance impedance along the distribution feeder. As a result, the line currents and damp transient oscillations is limited with a finite amount of active power circulating through the series and shunt inverter. A new protection scheme has been introduced which uses the abc-dq transformation of the scheme voltage to detect the presence of a short circuit fault and by comparing measurements at different locations provides discrimination between faults in different zones of protection associated with a particular micro-grid grid structure [15].

This scheme avoids the complications caused by the variations in potential fault currents associated with utility connected and isolated system of the micro-grid. It will provide a complimentary protection to conventional over-current relaying for scenarios, which produce significant fault currents. A protection scheme based on directional is proposed for micro-grids consisting of overcurrent synchronous based DG [16]. Directional overcurrent relays are used to protect the lines during both grid connected system and micro-grid system. The relay coordination problem is formulated as a Mixed Integer Selective Nonlinear Programming (MINLP) problem and is solved using system Particle Swarm Optimization (PSO). The directional overcurrent relays are coordinated with each other to ensure selectivity and reliability of the protection scheme. In addition, the protection of distributed micro-grid is very important to save the power grid structure $[17,18]$.

The concept of protection is to have the same protection strategies for both grid connected and autonomous system. Distributed micro-grid is interfaced to main power scheme by a fast static switch to protect a distributed micro-grid in both the modes of system against all types of faults. In general, a distributed microgrid can operate in both the grid connected mode and the islanded mode where the distributed micro-grid is interfaced to the main power scheme by a fast semiconductor switch called static switch. It is essential to protect a distributed micro-grid in both the grid-connected and the islanded modes of system against all types of faults. The major issue arises in island system with inverter-based sources. Inverter fault currents are limited by the ratings of the silicon devices to around 2 p.u. rated current. Fault currents in islanded inverter based distributed micro-grid may not have adequate magnitudes to use traditional over-current protection techniques.

This possibility requires an expanded protection strategy. The philosophy for protection is to have the same protection strategies for both islanded and grid-connected system. The static switch is designed to open for all faults. With the static switch open, faults within the distributed micro-grid need to be cleared with techniques that do not rely on high fault currents. 


\section{ANALYSIS OF SYMMETRICAL CURRENT COMPONENTS}

\section{A. System Topology}

A micro-grid usually consists of small segments of a distribution network connected to local distribution generation units and loads.

The system used in this study is an 11-line network with a load capacity of 2.75 MVA connected to a 5 MVA transformer. The phase loads of each bus are listed in Table 1. The system is protected using fuses and reclosers on the overhead lines and breakers on the underground lines.

The classical distribution system is shown with the protection devices in Fig. 2.

TABLE 1: BUS LOADS FOR THE MICRO-GRID

\begin{tabular}{|c|cccccc|c|}
\hline \multirow{2}{*}{ Name } & \multicolumn{2}{|c}{ Phase 1 } & \multicolumn{2}{c}{ Phase 2 } & \multicolumn{2}{c|}{ Phase 3 } & Type \\
\cline { 2 - 8 } & kW & kvar & kW & kvar & kW & kvar & \\
\hline SL_1 & 300 & 45 & 180 & 25 & 240 & 15 & Y_PQ \\
\hline SL_2 & 300 & 21 & 180 & 25 & 240 & 23 & Y_PQ \\
\hline SL_3 & 350 & 190 & 0 & 0 & 0 & 0 & D_I \\
\hline SL_4 & 100 & 15 & 60 & 5 & 80 & 5 & Y_PQ \\
\hline DL_1 & 0 & 0 & 148 & 24 & 0 & 0 & Y_I \\
\hline DL_2 & 102 & 51 & 0 & 0 & 0 & 0 & Y_Z \\
\hline DL_3 & 0 & 0 & 400 & 190 & 0 & 0 & Y_PQ \\
\hline
\end{tabular}

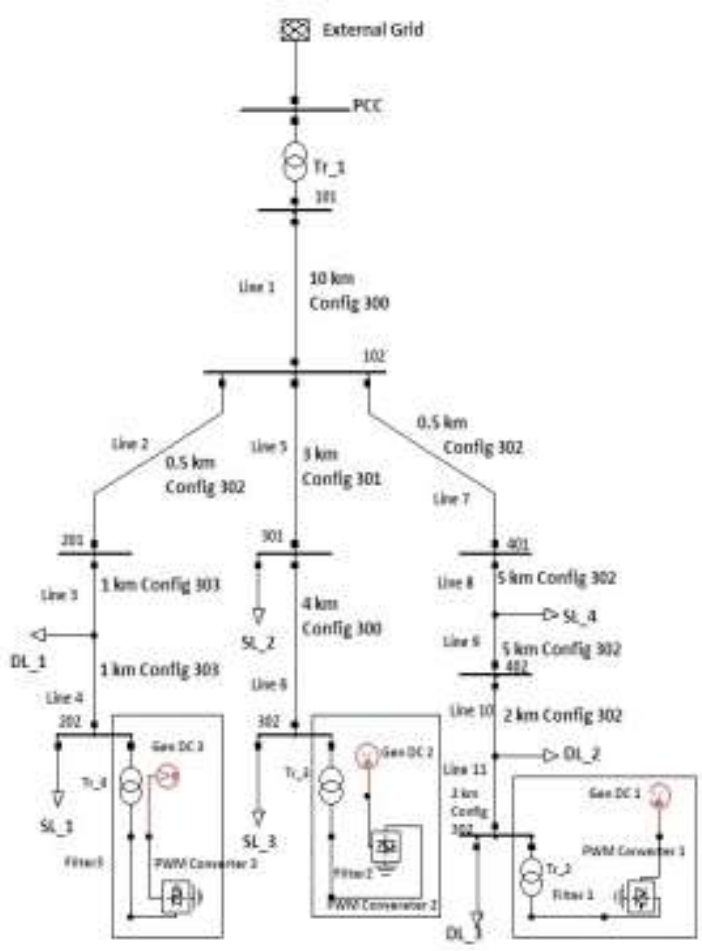

Figure -2. Single-line diagram of the examined microgrid.

\section{B. Simulation of the Micro-grid System}

In this study, the symmetrical current components at each line of micro-grid are evaluated and simulated using DIgSILENT PowerFactory. 
Three phase power flow study is conducted for three cases:

- on the original system

- on the grid connected micro-grid system

- on the islanded system

\section{Simulation Results}

The line currents for the three cases mentioned above are shown in Tables 2-4. The currents for normal operation are generally reduced with the addition of DG sources. In grid-connect mode, the line currents were very similar to those in the island mode with the exception of lines 1 and 2 which have no connected sources or loads in the island mode. Also, zero sequence and negative sequence currents in grid connected and islanded mod are shown in Tables 5 and 6 . In grid connect mode, the symmetrical component currents are very similar to those in the island mode.

TABLE 2: NORMAL LINE CURRENTS FOR GRID-CONNECTED WITHOUT DG SOURCES

\begin{tabular}{|c|cc|c|}
\hline LINE & A-PhASe (KA) & B-PhASe (KA) & C-PhASE (KA) \\
\hline $\mathbf{1}$ & 0.0727 & 0.0833 & 0.0378 \\
\hline $\mathbf{2}$ & 0.0211 & 0.0234 & 0.0162 \\
\hline $\mathbf{3}$ & 0.0211 & 0.0234 & 0.0162 \\
\hline $\mathbf{4}$ & 0.0211 & 0.0128 & 0.0162 \\
\hline $\mathbf{5}$ & 0.0372 & 0.0261 & 0.0164 \\
\hline $\mathbf{6}$ & 0.0162 & 0 & 0 \\
\hline $\mathbf{7}$ & 0.0148 & 0.0354 & 0.0054 \\
\hline $\mathbf{8}$ & 0.0148 & 0.0354 & 0.0054 \\
\hline $\mathbf{9}$ & 0.0071 & 0.0352 & 0.0054 \\
\hline $\mathbf{1 0}$ & 0.0071 & 0.0352 & 0.0054 \\
\hline $\mathbf{1 1}$ & 0.0071 & 0.004 & 0.0054 \\
\hline
\end{tabular}

TABLE 3: NORMAL LINE CURRENTS FOR GRID- CONNECTED WITH DG SOURCES.

\begin{tabular}{|c|c|c|c|}
\hline LINE & A-PhASe (KA) & B-PhASe (KA) & C-PHASE (KA) \\
\hline $\mathbf{1}$ & 0.0402 & 0.0475 & 0.0581 \\
\hline $\mathbf{2}$ & 0.0139 & 0.0092 & 0.0072 \\
\hline $\mathbf{3}$ & 0.0139 & 0.0092 & 0.0072 \\
\hline $\mathbf{4}$ & 0.0139 & 0.0189 & 0.0073 \\
\hline $\mathbf{5}$ & 0.0135 & 0.0238 & 0.0184 \\
\hline $\mathbf{6}$ & 0.033 & 0.0348 & 0.0335 \\
\hline $\mathbf{7}$ & 0.0148 & 0.0152 & 0.034 \\
\hline $\mathbf{8}$ & 0.0148 & 0.0152 & 0.034 \\
\hline $\mathbf{9}$ & 0.0193 & 0.0152 & 0.034 \\
\hline $\mathbf{1 0}$ & 0.0193 & 0.0152 & 0.034 \\
\hline $\mathbf{1 1}$ & 0.0194 & 0.0407 & 0.034 \\
\hline
\end{tabular}


Fundamental key issues and analysis of symmetrical current components in micro-grids

TABLE 4: NORMAL LINE CURRENTS IN ISLAND MODE

\begin{tabular}{|c|cc|c|}
\hline Line & A-PHASE (KA) & B-PHASE (KA) & C-PHASE (KA) \\
\hline $\mathbf{1}$ & 0 & 0 & 0 \\
\hline $\mathbf{2}$ & 0.0131 & 0.0089 & 0.007 \\
\hline $\mathbf{3}$ & 0.0131 & 0.0089 & 0.007 \\
\hline $\mathbf{4}$ & 0.014 & 0.0199 & 0.0071 \\
\hline $\mathbf{5}$ & 0.0131 & 0.022 & 0.0183 \\
\hline $\mathbf{6}$ & 0.034 & .0358 & 0.0342 \\
\hline $\mathbf{7}$ & 0.014 & 0.0149 & 0.031 \\
\hline $\mathbf{8}$ & 0.014 & 0.0149 & 0.031 \\
\hline $\mathbf{9}$ & 0.0189 & 0.015 & 0.031 \\
\hline $\mathbf{1 0}$ & 0.0189 & 0.015 & 0.031 \\
\hline $\mathbf{1 1}$ & 0.0195 & 0.0409 & 0.036 \\
\hline
\end{tabular}

TABLE 5: NORMAL SYMMETRECAL LINE CURRENTS FOR GRID- CONNECTED WITH DG SOURCES.

\begin{tabular}{|c|c|c|}
\hline Line & Negative Sequence Current (KA) & $\begin{array}{c}\text { Zero Sequence CurRent } \\
\text { (KA) }\end{array}$ \\
\hline $\mathbf{1}$ & 0.0074 & 0.0039 \\
\hline $\mathbf{2}$ & 0.0032 & 0.0019 \\
\hline $\mathbf{3}$ & 0.0032 & 0.0019 \\
\hline $\mathbf{4}$ & 0.0041 & 0.0049 \\
\hline $\mathbf{5}$ & 0.0040 & 0.0037 \\
\hline $\mathbf{6}$ & 0.0039 & 0.0023 \\
\hline $\mathbf{7}$ & 0.0071 & 0.0089 \\
\hline $\mathbf{8}$ & 0.0071 & 0.0088 \\
\hline $\mathbf{9}$ & 0.0062 & 0.0069 \\
\hline $\mathbf{1 0}$ & 0.0061 & 0.0069 \\
\hline $\mathbf{1 1}$ & 0.0065 & 0.0085 \\
\hline
\end{tabular}

TABLE 6: NORMAL SYMMETRECAL LINE CURRENTS FOR ISLANDED MODE

\begin{tabular}{|c|c|c|}
\hline Line & $\begin{array}{c}\text { Negative Sequence CurRent } \\
(\text { KA })\end{array}$ & $\begin{array}{c}\text { Zero Sequence CuRRent } \\
\text { (KA) }\end{array}$ \\
\hline $\mathbf{1}$ & 0 & 0.0036 \\
\hline $\mathbf{2}$ & 0.0028 & 0.0021 \\
\hline $\mathbf{3}$ & 0.0028 & 0.0021 \\
\hline $\mathbf{4}$ & 0.0041 & 0.0049 \\
\hline $\mathbf{5}$ & 0.0045 & 0.0040 \\
\hline $\mathbf{6}$ & 0.0042 & 0.0023 \\
\hline $\mathbf{7}$ & 0.0069 & 0.0086 \\
\hline $\mathbf{8}$ & 0.0070 & 0.0086 \\
\hline $\mathbf{9}$ & 0.0072 & 0.0081 \\
\hline $\mathbf{1 0}$ & 0.0071 & 0.0081 \\
\hline $\mathbf{1 1}$ & 0.0089 & 0.0049 \\
\hline
\end{tabular}




\section{CONCLUSION}

This paper presents a review on the researches and activities of micro-grid methodology. It introduces the current micro-grid research project, especially in Europe, United State, Japan and Canada. The fundamental key issues in micro-grids with respect to voltage and frequency flow grid control and protection are discussed in the first section that must be overcome for implementation micro-grid effectively. The main purpose of the paper is to analyze the symmetrical current components on a micro-grid to investigate the changes needed to the protection of the micro-grid systems. The results obtained from the simulations show that analysis of symmetrical current components can be a suitable choice for protecting micro-grids in the future.

\section{REFERENCES}

[1]. Nikkhajoei, Lasseter R. H, "Micro-grid Fault Protection Based on Symmetrical and Differential Current Componsents", Power System Engineering Research Center, 2006.

[2]. Nikkhajoei H, Lasseter R H, "Micro-grid Protection”, IEEE Power Engineering Society General Meeting, 2007, pp.1-6.

[3]. J. A. Pecas Lopes, C.L Moreira, F.O.Resende. 2005," Distributed micro-grids blackstart and distributed islanding system in Proc",15th PSCC, Liege, Belgium,

[4]. P. Piagi, R.H. Lasseter. June 2006, " Autonomous grid control of distributed micro-grids IEEE Power Engineering Society General Meeting",

[5]. A. N.D. Hatziargyriou, A.P Sakis Meliopoulos. 2002. Distributed energy sources: Fundamental key issues IEEE Power Engineering Society General Meeting.

[6]. Ming Sun, Juan Y, DENG B, "Analysis of Impact of DGs on Line Protection of Distribution Networks", Power System Technology, vol, 33(8), 2009, pp, 104-107.

[7]. T. Funabashi, R Yokoyama. June 2006, Distributed micro-grid field test experiences in Japan IEEE Power Engineering Society General Meeting, 18-22.

[8]. A. Engler. January 2005, Applicability of droops in LV grids International of Journal Distributed Energy Resources, Vol.1, no.1, pp.3-16.

[9]. Y. Hegazy., A.Chikhani. October 2003," Intention distributed islanding of distributed generation for reliability enhancement", CIGRE/IEEE PES International Symposium Quality and Security of Electric Power Delivery Schemas. pp. 208-213.

[10]. C. Marnay, F. Rubio, A. Sadsiqui. 2001. Shape of the distributed micro-grid, IEEE Power Engineering Society Winter Meeting. Vol.1, pp. 50-153.

[11]. F. Katiraei, M.R Iravani, P.W Lehn. January 2005," Micro-grid autonomous system during and subsequent to distributed islanding process", IEEE Trans on Power Delivery, 20(1): 248-257.

[12]. J. A. Pecas Lopes, Moreira CL, A.G Madureira. 2006. Defining grid control strategies for distributed micro-grids islanded system. IEEE Trans Power Schema, 21(2): 916-924.

[13]. W. E. Feero, D.C Dawson, J. Stevens. March 2006. White paper on protection issues of the distributed micro-grid concept, Consortium for Electric Reliability Methodology Solutions.

[14]. D. Mahinda Vilathgamuwa., L.P Chiang., L. Y. Wei. 2006. Protection of distributed micro-grids during utility voltage sags. IEEE Trans Ind Electron, 53(5): 1427-36.

[15]. H. AI-Nasseri, MA Redfern, RO Gorman. 2005. Protecting distributed micro-grid schemas containing solid-state converter generation. Int Conf Future Power Schema, pp.1-5.

[16]. H. Zeineldin, El-Saadany, M. Salama. 2006. Protective relay coordination for distributed micro-grid system using Particle Swarm Optimization. IEEE Transaction on Power Delivery, pp. 152-157.

[17]. R. Moxley and K. Fodero, "High-Speed Distribution Protection Made Easy: Communications-Assisted Protection Schemes for Distribution Applications," Proceedings of the 31st Annual Western Protective Relay Conference, Spokane, WA, October 2004.

[18]. Sohrab Mirsaeidi, Majid Gandomkar and Mohammad Reza Miveh, "Microgrid Protection Using a Designed Relay Based on Symmetrical Components”, Middle-East Journal of Scientific Research, Volume 11 Number (8), 2012, pp-1022-1028. 